\title{
THE ANAI,YSIS OF CIGARETTES, CIGARS AND TOBACCO, AND THE USE OF LLOYD'S REAGENT IN THE DETERMINATION OF NICOTINE.
}

\section{AZOR TIILRSTON.}

INTRODUCTION.

Some six months ago while in conversation with Hon. S. E. Strode. Commissioner in charge of the Dairy and Food Division of Ohio, the question of adulteration of cigarettes and other tobacco products came up and the statement was made by some one present that large quantities of tincture of opium were being purchased by manufacturers of this line of goods. An investigation was therefore ordered, not only as to opium, but as to medicinal substances in general. It fell to the lot of the writer to make whatever investigation as was deemed necessary.

The most natural thing to do was to look up the literature on the subject and, to my surprise, I was unable to find a published account of the analysis of cigarettes or cigars, although other tobacco products were fairly covered in reference to nicotine and some other constants. I therefore wrote to the Bureau of Chemistry, U. S. Department of Agriculture, where one naturally expects to obtain methods of analysis of practically everything, and again I was doomed to disappointment, the reply indicated that methods had not been developed for making analyses of cigarettes, although the department had made a few examinations of cigarettes with the view of determining whether or not they contained opium or arsenic.

I found in Wiley's Agricultural Analysis ${ }^{1}$ a statement in reference to opium and cigarettes as follows:- "It is believed, however, that opium is not often found in manufactured tobacco, and it has never been found in this laboratory in cigarettes, although all the standard brands have been examined for it."

I at once took the matter up with Dr. Wiley by correspondence, and received a reply as follows:-

"As far as I know opium, arsenic, etc., have never been found in cigarettes. This is a rumor which is constantly being floated, but is without general foundation. The cigarettes are harmful enough in themselves without seeking this cxtreme evil in them. None of the results referted to were ever published as far as I know. You can perhaps get more definite information concerning this investigation from $\mathrm{Mr}$. McElroy himself, as he is a practicing chemical patent attorney in this city. The address is K. P. McElroy, $918 \mathrm{~F}$ Street. I have no special data on the subject of the cigarette evil, but am unalterably opposed to the use of tobacco in any form, as I consider it an unclean, unhealthy habit which diminishes the vitality and the efficiency of the user, and is, morcover, an imposition on the public who do not use it."

Upon receipt of Dr. Wiley's letter it appeared I would corner the information I most desired, and I immediately wrote to Mr. McElroy for more light upon the subject. He promptly replied as follows:-

"I regret to say that I can give you very little information concerning the analyses of cigarettes at the present day. What analytical work I did was done very many years ago and the results were never published to my knowledge, having been made for the information of a congressional committee.

"About all I remember of the matter at present is that in the twelve or thirteen brands I analyzed I did not, of course, find morphine, arsenic, and other alleged ingredients. Neither did I find Alfalfa, a common rumor to the contrary notwithstanding. I found considerably more nicotine than expected."

1 Wiley's Agricultural Analysis, Vol. 111, 597. 
During this correspondence the inspectors had delivered to me a number of samples for analysis, and I decided to begin the investigation along lines that appeared most desirable the details of which follow.

Preparation of Samples:-The samples were not dried except as they were kept in the laboratory at a temperature of about $25^{\circ} \mathrm{C}$. Any attempt at artificial drying might be at the sacrifice of nicotine and was, therefore, not attempted. The samples were next powdered, so as to pass through a number 20 sieve. If finer so much the better, but it is some difficulty to obtain a powder of this fineness, even after passing the sample through a meat-chopper several times. In case of cigarettes the papers were removed and all particles of the filler carefully dusted off so as to obtain the papers as free from the filler as possible. Separate analyses being made of the papers.

The Analysis:-Determinations were made as follows:-Nicotine, ash, water soluble ash, water insoluble ash (by difference), hydrochloric acid insoluble ash, alkalinity of water soluble ash, alkalinity of water insoluble ash, opium and other drugs.

The same determinations were made of the papers, except for nicotine, and further tests were made. for nitrates in the papers.

RESLITS OF ANALYSIS OF TWO BRANIUS OF CHEAP CIGARS.

\begin{tabular}{|c|c|c|c|c|c|c|c|c|c|}
\hline No. & Brand & $\begin{array}{l}\text { Nico- } \\
\text { tine }\end{array}$ & $\begin{array}{l}\mathrm{H}_{2} \mathrm{O} \\
\mathrm{Sol} . \\
\mathrm{Msh}\end{array}$ & $\begin{array}{c}\mathrm{H}_{2} \mathrm{O} \\
\text { Ins. } \\
\text { Ash }\end{array}$ & $\begin{array}{c}\text { HCl, } \\
\text { Ins. } \\
\text { Ash }\end{array}$ & $\begin{array}{l}\text { Total } \\
\text { Ash }\end{array}$ & $\begin{array}{l}\text { Ash } \\
\mathrm{H}_{2} \mathrm{O} \\
\text { Sol. } \\
\mathrm{Ash}\end{array}$ & $\begin{array}{c}\text { Alk. } \\
\mathrm{H}_{2} \mathrm{O} \\
\mathrm{Ins} . \\
\Lambda \mathrm{sh}\end{array}$ & $\begin{array}{c}\text { Total } \\
\text { Alka- } \\
\text { Ash }\end{array}$ \\
\hline 4536 & $\begin{array}{c}\text { Cobs } \\
\text { Iavana }\end{array}$ & 1.48 & $7.1 \tilde{5}$ & 14.88 & 2.36 & 22.03 & 4.15 & 28.85 & 33.00 \\
\hline 4539 & Plumes & 1.26 & 5.83 & 14.58 & 4.27 & 20.41 & 3.60 & 29.90 & 33.50 \\
\hline \multicolumn{2}{|c|}{ Average } & 1.37 & 6.49 & 14.73 & 3.31 & 21.22 & 3.87 & 29.38 & 33.25 \\
\hline
\end{tabular}

RESULTS OF ANALYSIS OF THREE SAMPIES OF TOBACCO IEAVES WITH MIDRIBS REMOVED.

\begin{tabular}{|c|c|c|c|c|c|c|c|c|c|}
\hline No. & Habitat & $\begin{array}{l}\text { Nico- } \\
\text { tinc }\end{array}$ & $\begin{array}{l}\mathrm{H}_{2} \mathrm{O} \\
\text { Sol. } \\
\text { Ash }\end{array}$ & $\begin{array}{c}\mathrm{I}_{2} \mathrm{O} \\
\mathrm{Ins} . \\
\mathrm{Ash}\end{array}$ & $\begin{array}{c}\mathrm{HCI} \\
\text { Jns. } \\
\text { ヘsh }\end{array}$ & $\begin{array}{l}\text { Total } \\
\text { Ash }\end{array}$ & $\begin{array}{l}\text { Alk. } \\
\mathrm{H}_{2} \mathrm{O} \\
\mathrm{Sol} . \\
\mathrm{Ash}\end{array}$ & $\begin{array}{c}\text { Alk. } \\
\mathrm{H}_{2} \mathrm{O} \\
\text { Ins. } \\
\text { Ash }\end{array}$ & $\begin{array}{l}\text { Total } \\
\text { Alka- } \\
\text { linity } \\
\text { Ash }\end{array}$ \\
\hline 4540 & Ohio & 3.24 & 8.42 & 13.76 & 2.33 & 22.18 & 4.80 & 24.55 & 29.35 \\
\hline 4611 & Vir. & 3.38 & 5.17 & 6.79 & 2.04 & 11.96 & 4.15 & 9.95 & 14.10 \\
\hline 4612 & Vir. & 2.41 & 3.97 & 8.39 & 2.49 & 12.36 & 1.55 & 13.05 & 14.60 \\
\hline \multicolumn{2}{|c|}{ Average } & 3.04 & 5.85 & 9.65 & 2.29 & 15.50 & 3.50 & 15.85 & 19.35 \\
\hline $\begin{array}{l}\text { Ribs } \\
\text { from }\end{array}$ & & & & & & & & & \\
\hline 4540 & & & .53 & 8.82 & .43 & 18.35 & 6.40 & 18.20 & 24.60 \\
\hline
\end{tabular}

No. 4612 was a blcached tobacco used for the manufacture of cigarettes.

METHODS OF ANALYSIS.

Nicotine:-As the amount of nicotine present determines the strength of the tobacco this estimation is of great importance.

Numerous methods have been proposed for the determination of nicotine, but they all practically are included in three divisions.

The Kissling ${ }^{2}$ method is the official method of the Association of Official Agricultural Chemists and consists in making the sample alkaline and extracting with

2 U. S. Dept. Agr. Bureau of Chemistry Bulletin 107 (Revised), 32. 


\begin{tabular}{|c|c|c|c|}
\hline & 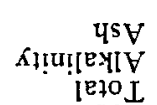 & 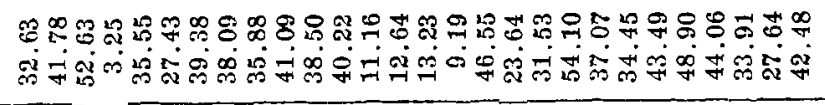 & : \\
\hline & 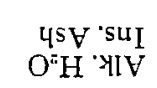 & 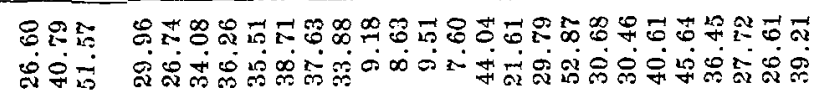 & $\begin{array}{l}\sharp \\
\dot{0}\end{array}$ \\
\hline & $\begin{array}{l}\text { YS } V \text { 'IOS } \\
\mathrm{O}^{*} \mathrm{H} \cdot \text { भI }\end{array}$ & $\begin{array}{l}\sigma \\
0 \\
0\end{array}$ & $\stackrel{20}{2}$ \\
\hline  & $\begin{array}{r}4^{\mathrm{s}} \mathrm{V} \\
\text { [ש? }\end{array}$ & 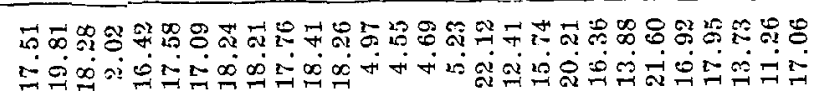 & $\begin{array}{l}\mathscr{\Xi} \\
\stackrel{ \pm}{ \pm}\end{array}$ \\
\hline A & $\begin{array}{l}\text { Ys } \\
\text { suI } \\
\text { DH }\end{array}$ & 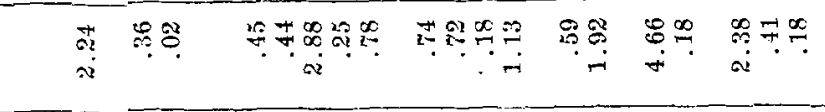 & $\mathfrak{i}$ \\
\hline & $\begin{array}{l}\text { 4s } \\
\text { 'StII } \\
\mathrm{O}^{2} \mathrm{H}\end{array}$ & 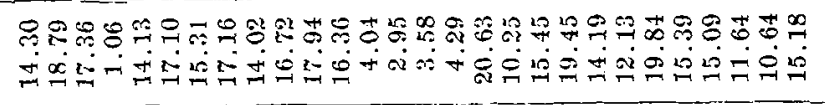 &  \\
\hline & $\begin{array}{l}\text { ys } \\
\text { IOS } \\
\mathrm{O}^{2} \mathrm{H}\end{array}$ & 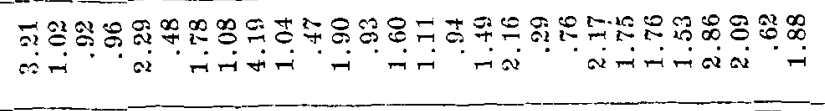 & $\stackrel{4}{2}$ \\
\hline & 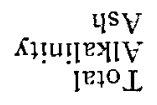 & 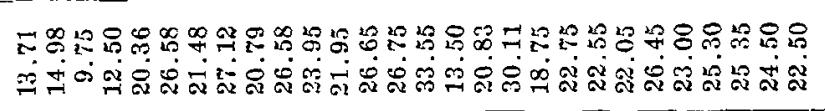 & 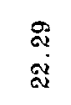 \\
\hline & 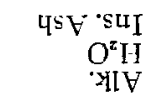 & 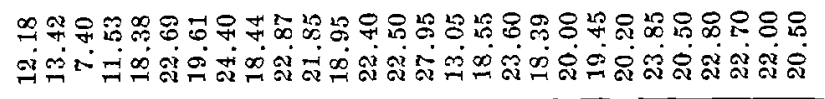 & $\begin{array}{l}28 \\
\stackrel{8}{0} \\
\stackrel{0}{7}\end{array}$ \\
\hline &  & 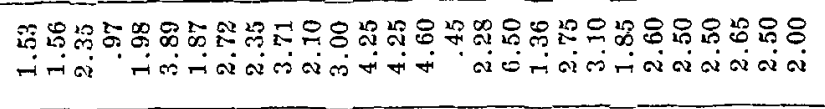 & $\begin{array}{l}\sharp \\
\stackrel{*}{*}\end{array}$ \\
\hline $\mid$ & $\begin{aligned} \text { ySH } \\
\text { Iejo }\end{aligned}$ & 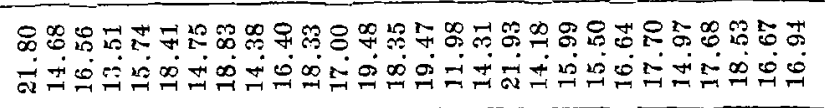 & $\begin{array}{l}\infty \\
\stackrel{\infty}{0} \\
\ddot{n}\end{array}$ \\
\hline & $\begin{array}{l}4 \text { sv } \\
\text { suI } \\
1 \mathrm{HH}\end{array}$ & 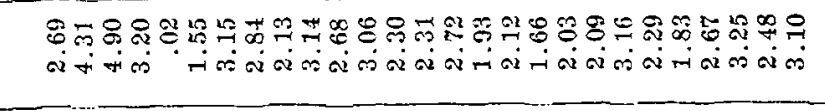 & $\underset{m}{\stackrel{m}{*}}$ \\
\hline & $\begin{array}{l}\text { पs } \\
\text { suI } \\
\mathrm{O}^{2} \mathrm{H}\end{array}$ & 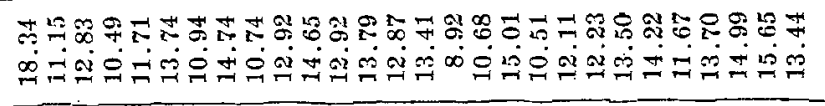 & $\begin{array}{l}\stackrel{2}{\circ} \\
\stackrel{2}{\sim}\end{array}$ \\
\hline & $\begin{array}{l}\text { ys } \\
\text { los } \\
\mathrm{O}^{2} \mathrm{H}\end{array}$ &  & $\begin{array}{l}\infty \\
\substack{\infty \\
\text { in }}\end{array}$ \\
\hline & 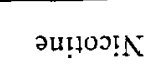 & 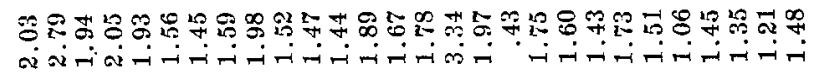 & $\stackrel{9}{\oplus}$ \\
\hline & pursg & 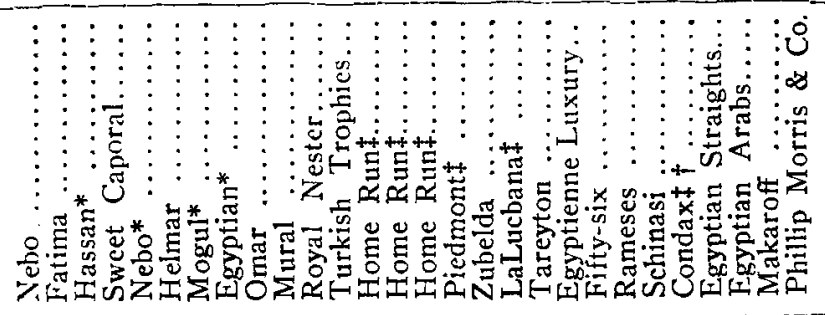 & 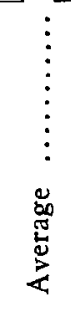 \\
\hline & $0 \mathrm{~N}$ &  & \\
\hline
\end{tabular}


ether, evaporating the ether, and distilling the extract in a current of steam. The distillate is titrated with standard acid.

The Keller ${ }^{3}$ method-The nicotine is extracted with proper solvents and air passed through the extract, to expel ammonia, and the extract finally titrated with standard acid.

The Bertrand \& Javillier ${ }^{4}$, or Silicotungstate method-As in the Kissling or similar methods the nicotine is extracted from the tobacco and the extract distilled in a current of steam and then the nicotine precipitated from the distillate as nicotine silicotungstate, a rose white salt with the following formula: $-2 \mathrm{C}_{10} \mathrm{I}_{14} \mathrm{~N}_{2}$ $2 \mathrm{H}_{2} \mathrm{O} \mathrm{SiO}{ }_{2} 12 \mathrm{WO}_{3}+5 \mathrm{H}_{2} \mathrm{O}$. This salt on being ignited leaves a residue or $\mathrm{SiO}_{2}$ and $\mathrm{WO}_{3}$ from which is calculated the weight of nicotine originally present. This method of analysis was used for the determination of nicotine as herewith tabulated except the first extracting was omitted and the nicotine determined in the tobacco by directly distilling in a current of stean and following out Chapin's" directions modified to read as follows:-Weigh out exactly 5 grams of the sample and wash, with about $25 \mathrm{cc}$. of water, into a $500 \mathrm{cc}$. Kjeldahl flask; add 1 to $1 \frac{1}{2}$ grams of paraffin, a few small pieces of pumice and $5 \mathrm{cc}$. saturated solution of sodium hydroxide. Distil in a rapid current of steam, through a condenser and adapter, into $10 \mathrm{cc}$. of dilute hydrochloric acid ( $\mathrm{I} / 4$ ) into a $1500 \mathrm{cc}$. flask. When distillation is well started, apply heat to the distilling flask so as to keep the volume as low as practical. Distil until the distillate measures about 1000 cc., or when treated with a drop of silicotungstic acid and a drop of hydrochloric acid no opalescence is produced. Make the distillate up to exactly $1000 \mathrm{cc}$., or some other convenient volume, with distilled water. Filter and place $100 \mathrm{cc}$. of filtrate in a $250 \mathrm{cc}$. beaker and add $3 \mathrm{cc}$. dilute hydrochloric acid $(\mathrm{I} / 4)$ or more if necessary to. make the solution distinctly acid. Add $1 \mathrm{cc}$. of a 12 per cont. solution of silicotungstic acid for each 0.01 gram nicotine supposed to be present. Stir thoroughly and let stand for eighteen hours. Filter on an ashless filter and wash with dilute hydrochloric acid, $1 \mathrm{cc}$. concentrated acid to $1000 \mathrm{cc}$. water, until the filtrate is free of silicotungstic acid. Transfer the wet paper and precipitate to a weighed platinum crucible, using a scrap of moistened filter paper to transfer any precipitate which may have crept up the sides of the funnel; dry, carbonize and break up the precipitate with a platinum wire and finally cover the crucible and apply full heat of a Bunsen burner for fifteen minutes. Cool in a desiccator and weigh. The weight of the residue multiplied by 0.114 afford the nicotine in the aliquot taken for precipitation, and from this amount the percentage may be calculated.

Instead of precipitating with silicotungstic acid Emery ${ }^{8}$. proposed to determine the amount of nicotine in the distillate by polarization and others have proposed to precipitate the nicotine with mercuric potassium iodid. It appears to the writer that the silicotungstic method is less liable to errors and it is susceptible of concordant results on duplication.

THE USE OF LLOYD'S REAGENT IN TIE DETERMINATION OF NICOTINE.

This is merely a preliminary report on the determination of nicotine with Lloyd's Reagent as lack of time has prevented a thorough investigation, althougls

3.J. Chem. Soc., 1899, Vol, 76, 11, 193. Pro. A. Ph. A., 1900, Vol, 48, 392.

4 J. Chem. Soc., 1909, Vol. 96, 11, 450. Chem. Abs. 1909, Vol. 3, 1382 and 2103.

5 U. S. Dept. Agr. Bureau of Animal Industry Bulletin 133 .

6 J. Am. Chem. Soc., 1904, Vol. 26, 1113. 
sufficient work has been done to predict that a successful method might be worked out.

So far I have been unable to make close duplications and without going into details as to the different experiments made I will give the amount of nicotine found by the use of ILloyd's Reagent and by using silicotungstic acid:-

$\begin{array}{rcc}\text { No. } & \text { Silicotungstic Method } & \text { Lloyd's Reagent } \\ 4524 & 2.05 & 1.80 \\ 4525 & 1.93 & 1.99 \\ 4527 & 1.45 & 1.99 \\ 4530 & 1.52 & 1.18 \\ & & 2.06 \\ 4528 & 1.59 & 1.65 \\ 4535 & 1.97 & 1.51 \\ 4529 & 1.98 & 1.75 \\ & & 1.99 \\ 4532 & 1.44 & 1.97\end{array}$

There have been a number of interesting articles ${ }^{7}$ published in reference to Lloyd's Reagent which should be read by interested parties.

All methods of extracting the alkaloids of tobacco, includes the four alkaloids,nicotine, nicotimine, nicoteine, and nicotilline. The three latter existing in such small quantities that they do not make much practical difference and usually the total amount of alkaloids extracted from tobacco is considered nicotine; however, as nicotine and nicotimine are volatile in a current of steam and the other two are not, by the distillation method the two non-volatile alkaloids are eliminated.

I find sulphomolybdic acid gives a blue coloration with nicotine, which might be easily mistaken for morphine, as practically the same coloration is produced with this reagent with both alkaloids. A drop of the reagent should be directly applied to the pure nicotine or to the solids containing nicotine-such as tobacco and tobacco extracts. The color is produced more rapidly if the substance is slightly warmed.

Ash:-Weigh exactly 2 grams of the sample in a platinum pan and incinerate. Any particles carbon can be removed by adding a few drops of water to the ash and after drying ignite for a few minutes. The average ash obtained from three samples of leaf tobacco was 15.50 , from two samples of cigars 21.22 , and from twenty-eight samples of cigarettes 18.81 per cent.

Alkalinity of Water-Soluble and Water-Insoluble Ash:-The water-soluble ash is determined by dissolving, in hot water, the soluble portion from the ash as above determined and titrating with $\mathrm{N} / 10$ acid, using methyl orange as indicator. The alkalinity of water-soluble ash is reported as the number of cubic centimeters of decinormal acid required to neutralize the ash from one gram of the sample.

The water-insoluble ash is dissolved in $5 \mathrm{cc}$. normal hydrochloric acid and the excess of acid estimated by titrating with decinormal alkali. The number of cubic centimeters of decinormal alkali used deducted from 50 will give the alkalinity of the water-insoluble ash. In a few cases it will be necessary to use $10 \mathrm{cc}$. normal acid as the alkalinity occasionally runs very high.

Hydrochloric Insoluble Ash:-Is determined by adding concentrated hydrochloric acid to the solution after determining alkalinity of the water-insoluble ash. Pass the bulk of the solution through an ashless filter and add concentrated hydro-

7 J. Am. Chem. Soc, 1913, Vol. 35, 837. Am. Druggist, 1913, Vol, 61, 234.

J. Am. Ph. Association, 1914, Vol. 3, 625-630. 
chloric acid to the residue and wash the insoluble portion on the filter with distilled water. Incinerate the filter with residue in a platinum crucible. Cool, and weigh.

Opium and Other Drugs:-Macerate a few grams of the sample with alcohol for two or three hours. Filter and evaporate the filtrate to dryness. Extract the residue with dilute sulphuric acid and complete the investigation by shaking out according to Fuller's ${ }^{8}$ scheme of analysis for separation and detection of substances in medicinal products.

The current report is that cigarettes contain opium or some form of "dope"; however, the brands I examined were free of added medicinal substances, barring calcium, magnesium and nitrates found in the papers.

Referring, again, to sulphomolybdic acid test for nicotine, I wish to call your attention to the fact that morphine might be easily mistaken for nicotine. For instance, after shaking out the alkaline solution with petroleum ether, for nicotine, and then with a mixture of chloroform and alcohol $(2: 1)$ for morphine and evaporating the solvent $I$ added a drop of sulphomolybdic acid to the residue and a blue color was at once produced, indicating morphine. As the brand of cigarettes tested was manufactured by a company of high reputation it did not appear probable they would use opium in their goods. Therefore, I extracted the nicotine from a distillate of known purity and applied sulphomolybdic acid to the residuc and the bluc coloration was at once produced.

If, for any reason, only one test is to be applied to the extract for the detection of morphine, use formaldehyde-sulphuric acid (10 cc. formaldehyde solution to $50 \mathrm{cc}$. concentrated sulphuric acid). A deep purple color indicates morphine and no coloration is produced with nicotine.

\section{CIGARETTE PAPERS.}

So far as $I$ know nearly all cigarette papers have chemical fillers added, presumably to improve their burning qualities; however, if the ingredients are harmless there should be no particular objection to their use.

Prominent manufacturers kindly furnished the analysis of two brands of cigarette papers and, as I have not been able to find this subject covered in the published literature I consider them of sufficient interest to reproduce same in this paper.

"ANALYSIS OF CIGARETTE PAPERS.

\begin{tabular}{|c|c|c|}
\hline Moisture & $\begin{array}{c}\text { Austrian } \\
4.30\end{array}$ & $\begin{array}{c}\text { French } \\
4.62\end{array}$ \\
\hline \multicolumn{3}{|l|}{ Ash } \\
\hline Calcium oxide. & 4.95 & 5.12 \\
\hline Magnesium oxide... & 88.80 & 84.02 \\
\hline Iron, alumina and silica exides. & 4.00 & 4.68 \\
\hline Chlorides $\ldots \ldots \ldots \ldots \ldots$. & trace & trace \\
\hline 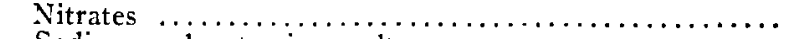 & none & none \\
\hline Sodium and potassium salts $\ldots \ldots \ldots \ldots \ldots \ldots \ldots \ldots$ & trace & trace \\
\hline 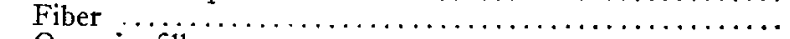 & linen & linen \\
\hline Organic fllers....... & starch & starch \\
\hline Soluble constituents.. & alkaline & alkaline \\
\hline Carbonates in filler as $\mathrm{CO}_{2}$, at least.... & 2.00 & 2.00 \\
\hline
\end{tabular}

"The papers were all what would be teclnically known as 'very moderately' sized as they carry small amount of starch, along with the filler which was composed of varying amounts

${ }^{8}$ Fuller's Qualitative Analysis of Medicinal Substances. 
of calcium, aluminum and magnesium oxides and carbonates. There was also present small amounts of iron and silica which would be present from the wash water used in the preparation of the pulp or in many other ways.

"The fiber present in the pulp was found to be composed of linen, very well pulped except for a very few bunches of undigested or unbeaten fiber which it is impossible to overcome. No test for other fibers was obtained. No acids, sulphur compounds or chlorine was found which might have come from the process of manufacture. The paper gave an alkaline reaction due to the filler used which was composed of calcium, aluminum and magnesium carbonates and oxides. The carbonates present were equal to at least $75 \%$ of the ash and probably more, but it was impossible to determine this very accurately. No impurities other than those mentioned were found. The moisture found was of varying weight, due to the fact that paper of the variety examined has a tendency to hold moisture proportionate to the humidity of the atmosphere of the date of examination."

I wish to call particular attention to the small amount of ash shown by these analyses compared with the amount actually found by the writer in twenty-eight samples which yiclded an average percentage of 14.93 .

\section{NITRATES IN PAPERS.}

It appears that the majority of manufacturers object to paper containing nitrates.

Nitrates may be detected by applying the diphenylamine test as follows:Take one drop diphenylamine test solution on a glass rod and draw the rod lightly and quickly across the paper. Hold the paper to the light and within five or ten seconds a blue coloration is produced in case nitrates are present. If a large quantity of the nitrate is present the coloration forms immediately. The diphenylamine test solution may be prepared after Withers \& Gray's formula, ${ }^{9}$ which is as follows:- -0.7 gram of diphenylamine is dissolved in $60 \mathrm{cc}$. concentrated sulphuric acid and $28.8 \mathrm{cc}$. of distilled water. The mixture is thoroughly cooled and $11.3 \mathrm{cc}$ concentrated hydrochloric acid are added slowly.

The papers of only four brands out of twenty-eight tested, responded to this test for nitrates.

In closing, I wish to acknowledge the helpful suggestions of Prof. John $U$. I loyd while experimenting with Lloyd's Reagent; also to those who kindly and promptly replied to my letters when seeking information on certain points and to the manufacturers in furnishing data in reference to cigarette papers.

\section{ESTIMATION OF CALOMEL.}

\section{R. I. GRANTHAM.}

The iodometric method for the estimation of calomel is the most expeditious and convenient one. This method, however, cannot be applied generally, especially in the analysis of calomel tablets or similar preparations which contain in addition to the mercury salt various other ingredicnts. In order to find a reliable method for estimating the calomel in such products the following methods were tried by which reliable results were obtained:-

\section{METHOD I.}

$0.3 \mathrm{gm}$. of calomel or an amount of the powdered tablets equivalent to $0.3 \mathrm{gm}$. of calomel is transferred to a 6 ounce glass stoppered bottle. Any alkali present

\footnotetext{
9 J. Am. Chem. Soc. (1911), Vol. 33, 708.
} 